\author{
Víctor Silva Echeto \\ Universidad de Playa Ancha, Chile
}

\author{
Rodrigo Browne Sartori \\ Universidad Austral de Chile
}

\title{
Las ciudades invisibles: heterotopías nómadas y postpatriarcado
}

\begin{abstract}
Resumen: Muchas ciudades se pueden encontrar en una ciudad: algunas visibles $y$ otras invisibles, pero todas ellas se producen en lo heterotópico del espacio otro (heterogéneo y nómada). Diversas formas de imaginar las ciudades (desde la literatura, el cine, la música) permiten transgredir las ciudades postpatriarcales, desde una concepción del feminismo nómada, rizomática y transversal, y responderles creativa y estéticamente a las ciudades que se han ido diseñando bajo el alero del capitalismo tardío: homogéneas, (in)diferentes, no lugarizadas, machistas (sin identidad, ni relaciones, ni historias). Frente a ellas, sin duda, surge y brota la figura de las ciudades otras, de la multiplicidad de las diferencias y las singularidades, de lo dejado de lado: los estudios de género y la reivindicación que ellos hacen (ciudades sexuales y nómadas), ciudades diferentes, ambiguas, ambivalentes, excéntricas, deseantes y heterotópicas (de espacios heterogéneos, cambiantes y fracturados).

Palabras clave: ciudades invisibles; nomadismo; heterotopía; patriarcado; postpatriarcado.
\end{abstract}

Copyright (C) 2009 by Revista Estudos Feministas.
"La ciudad existe y tiene un simple secreto: sólo conoce partidas y no retornos" Italo Calvino

"Viajo para conocer mi geografía" Nota de un loco (Marcel Réja)
1 FOUCAULT, 1986.

2 VATTIMO, 1998.

\section{Introducción}

La noción de heterotopía - planteada por Michel Foucault ${ }^{1}$ y retomada por Gianni Vattimo ${ }^{2}$ que se refiere a la yuxtaposición de tiempos y espacios (de vivir en diferentes temporalidades, por ejemplo, entre lo pre y lo postmoderno) 
${ }^{3}$ RODRÍGUEZ MONEGAL, 1968, p. 6.
- es un concepto que permite acercarnos a la pregunta de ¿cómo nos arreglamos para vivir a la vez en la ciudad real y la ciudad imaginada? Porque aunque todas las ciudades, históricamente, presentan una tensión entre lo visible y lo invisible, entre lo que se sabe y lo que se sospecha, lo que ha cambiado en la urbe actual es la complejidad para responder a esa interrogante. Hay una primera oscilación entre lo visible y lo invisible y es la tensión entre la ciudad experimentada físicamente y la ciudad imaginada en relatos o en canciones. Es decir, la que se narra en novelas, como es el caso de Yoknapatawpha de William Faulkner, Comala de Juan Rulfo, Santa María de Juan Carlos Onetti o Macondo de Gabriel García Márquez.

Por ejemplo, Emir Rodríguez Monegal ${ }^{3}$ escribe sobre algunos autores rioplatenses y sus proyecciones en ciudades imaginadas: "Como Florencio Sánchez y Horacio Quiroga, Juan Carlos Onetti es de aquellos escritores uruguayos cuya obra se proyecta tempranamente sobre ambos márgenes del Plata". No sólo porque Onetti "haya vivido unos veinte años en Buenos Aires (los años de su madurez literaria) y haya publicado allí cinco de sus mejores novelas, sino por la muy principal razón de que el mundo que crea en sus narraciones es el de la ciudad rioplatense de este siglo". Puede llamarse "Montevideo (como en El pozo) o Buenos Aires (como en Tierra de nadie) o Santa María (como en casi todas las demás), la ciudad que describe Onetti, la ciudad en que viven y mueren sus personajes, la ciudad con la que sueña hasta hacer soñar a sus lectores, es una ciudad rioplatense".

También están las ciudades que se relatan en las páginas de la prensa, en las emisiones de radio y las que aparecen en las pantallas de televisión. Hay otro tipo de ciudades como son las ciudades otras o alter ciudades, que son las urbes que están habitadas por las diferencias de distinto tipo como, por ejemplo, las sexuales o étnicas. Están las urbes donde los relatos, las imágenes, los sueños, los amores, las tristezas se hacen visibles en sus muros, desde los graffitis como espacios de comunicación. En resumen, son muchas las ciudades que se pueden encontrar en una ciudad, algunas visibles otras invisibles, pero todas ellas se producen en la heterogeneidad y diferencia del espacio otro (heterotópico). Nos damos cuenta de que vivimos en ciudades porque nos apropiamos de sus espacios: casas y parques, calles y viaductos. Pero no las recorremos únicamente a través de los medios de transporte, que en definitiva son medios de comunicación, sino también con los relatos e imágenes que visibilizan lo invisible.

En este escrito todas esas ciudades irán ocupando sus espacios. Confrontaremos la fría, homogénea y solitaria 
${ }^{4}$ CALVINO, 1999.

${ }^{5}$ CALVINO, 1999, p. 14

${ }^{6}$ CALVINO, 1999, p. 14

${ }^{7}$ CALVINO, 1999, p. 15

\footnotetext{
${ }^{8}$ BRAIDOTTI, 2004, p. 57.

9 JAMESON, 1996.
}

ciudad del capitalismo tardío postpatriarcal, con la vivida, alegre, nómada y carnavalizante urbe de la diferencia sexual.

\section{Ciudades invisibles y ciudades postpatriarcales}

En Las ciudades invisibles de Italo Calvino ${ }^{4}$ no se "encuentran ciudades reconocibles". Cada una de ellas tiene un nombre de mujer y aunque el escritor sostenga que son todas inventadas, esas ciudades deberían de servir como punto de partida para reflexionar sobre las ciudades contemporáneas que se escapan de las maquetas y los mapas que las intentaron proyectar. La intención de Calvino es contrarrestar esos espacios invisibles, heterogéneos, cambiantes, con la homogeneidad urbana a la que se dirigía la modernidad. Siguiendo sus palabras: "hoy (...) todo el mundo tiende a uniformarse". ${ }^{5}$ Kublai Kan, el emperador melancólico de los Tártaros, ha comprendido que su ilimitado poder cuenta poco "en un mundo que marcha hacia la ruina, un viajero imaginario", como es Marco Polo, le habla de "ciudades imposibles", como es el caso de "una ciudad microscópica que va ensanchándose y termina formada por muchas ciudades concéntricas en expansión, una ciudad telaraña suspendida sobre un abismo, o una ciudad bidimensional". ${ }^{\circ}$

El texto de Calvino es "como un último poema de amor a las ciudades", cuando se hace "cada vez más difícil vivir" en ellas. ${ }^{7}$ Además de los nombres femeninos y su relación con éstas, el autor invita a transgredir y subvertir desde las reflexiones sobre las ciudades postpatriarcales que se han ido diseñando bajo el alero del capitalismo tardío: homogéneas, (in)diferentes, no lugarizadas (sin identidad, ni relaciones, ni historias). Frente a ellas, sin duda, hay que oponer las ciudades otras, de la multiplicidad de las diferencias y las singularidades, por ejemplo, las de género. Éstas son diferentes, ambiguas, ambivalentes, nómadas, excéntricas, deseantes y heterotópicas (de espacios heterogéneos, cambiantes y fracturados).

A las nociones de postpatriarcado se refieren algunas autoras y autores, conteniendo el concepto una clara vinculación con los planteamientos post (modernista, estructuralista) de finales del siglo pasado. Rosi Braidotti ${ }^{8}$ la vincula con la concepción del capitalismo tardío de Fredric Jameson:" "se trata de una descripción adecuada del mundo de hoy y, a mi juicio, de una reacción constructiva ante la situación histórica específica que atraviesan las sociedades postindustriales luego de la decadencia de las esperanzas modernistas". Las ciudades postpatriarcales 
10 BRAIDOTTI, 2004, p. 57.

1 JAMESON, 1996, p. 54. contienen los signos de la decadencia de la modernidad y del capitalismo industrial, se encuentran "'limpias' gracias a los edificios de metal y de plexiglás que reemplazaron a las antiguas fábricas, los complejos habitacionales de los obreros o las escuelas, como si una máscara ocultase hoy la ineluctable decadencia de nuestro espacio menos favorecido". ${ }^{10}$ El principio de Martín Heidegger sobre la "senda del bosque" ha sido destruido irrevocable e irremediablemente por el capitalismo tardío, por la revolución verde, el neocolonialismo y las grandes conurbaciones que despliegan sus autopistas elevadas sobre los viejos campos y los solares abandonados. De esa forma, la "casa del ser" de Heidegger se ha convertido en territorio público o en unos fríos o miserables edificios de alquiler llenos de ratas. ${ }^{11}$

Por tanto, en un momento histórico de crisis de lo urbano, de megalópolis que se salen de las maquetas, de las ciudades continuas, uniformes que van cubriendo el mundo, de urbes de millones de recorridos y trazados, del incremento de la población en los países menos favorecidos del planeta y, por lo mismo, pobladas de ratas, de basurales, se produce, evidentemente, el descenso de la calidad de vida de sus habitantes, quienes ya no son más ciudadanas y ciudadanos sino simples datos numéricos de una tarjeta de crédito o mendigos sin nombres ni cuerpos. Esta situación conduce a que multitudes de seres humanos que viven en la pobreza, no tengan otra alternativa que emigrar y deambular por países y culturas. El afuera penetra en el adentro, los márgenes en los centros... El tercer mundo y el primero ya se encuentran uno en el otro.

Esos migrantes, como nuevos bárbaros y nómadas, desafían - con sus mapas nocturnos - a los servicios de extranjería, cruzan por las noches los campos y las culturas, desterritorializan la identidad estática del territorio y del esencialismo cultural. Sin embargo, aun los pobres o marginados no pueden prescindir de lo global. Cuando los migrantes latinoamericanos llegan al norte de México o al sur de Estados Unidos, descubren que la empresa donde consiguen trabajo es coreana o japonesa. Además, muchos de los que salieron de su país debieron llegar a esa decisión extrema porque "la globalización" cerró puestos de trabajo en Perú, Colombia o Centroamérica, o sus efectos combinados con dramas locales - volvieron demasiado insegura a la sociedad en la que siempre vivieron. ${ }^{12}$

Así las cosas, se ha dicho que Nueva York es "Ia estación terminal de la civilización occidental", mientras que México DF es el "último puerto de los delirios de Occidente en su versión tercermundista". México DF tiene más de 20 millones de habitantes mientras que Tokio tiene más de 25 y São Paulo ya superó los 20. 
Es por eso que América Latina no está ajena a estos procesos y el crecimiento exponencial de ciudades como São Paulo y México DF no es más que uno de los tantos ejemplos de ciudades inmanejables para personas que sólo pueden trazar circuitos fragmentarios, breves y fugaces, pero perdiendo la dimensión totalizadora de la ciudad al abarcar sólo el estrecho recorrido de lo cotidiano.

En el caso de la ciudad de México, varios millones de personas ocupan entre dos y cuatro horas diarias transportándose en metro, autobuses, taxis y automóviles particulares. Se realizan alrededor de 30 millones de viajespersona por día. Es bueno recordar que en los últimos cincuenta años, la expansión de la ciudad de México la elevó de 1.600 .000 personas a más de 20 millones, de un Distrito Federal acotado a un área metropolitana de 1.500 kilómetros cuadrados. Otra característica de los países latinoamericanos es la concentración de la población en algunas pocas ciudades, generalmente, las capitales. Por ejemplo, Santiago de Chile pasó en los últimos 40 años de más 1 millón de personas a 6 millones en el año 2002. Eso representa el 40 por ciento de la población chilena (que supera los 15 millones de habitantes).

\section{Ciudades de la comunicación y la información}

Las ciudades también son relatadas por los periódicos, la radio, el cine y la televisión. La relación entre ciudades y comunicación ha sido muy estrecha desde prácticamente el siglo XIX. El pensamiento de la sociedad en la ciudad moderna inspiró las primeras concepciones de una "ciencia de la comunicación". También, hay que tener en cuenta, que desde los inicios de la prensa, en sus páginas se han encontrado múltiples narraciones sobre las ciudades. Acto seguido, los medios de comunicación han sido testigos del desarrollo y crecimiento de las urbes, y sus relatos han permitido también imaginarnos esas ciudades comunicacionales e informativas.

Hay ciudades pecados (como en el cómic de Frank Miller y en la película de Miller y Robert Rodríguez) donde sus recorridos están acechados por el peligro de la violencia, la droga y el alcohol. Algunas de las ciudades que se relatan actualmente desde las redes postmediáticas de comunicación están enmarcadas en la "cultura del miedo", propician, por tanto, el encierro de las ciudadanas y los ciudadanos, el miedo hacia el otro que no tiene rostro y, por ello, se le teme aún más. Son virtuales y simuladas. Las ciudades comunicacionales e informativas tienen su contrapartida en las urbes de control, pobladas de rejas, alarmas y 
13 Jacques DERRIDA y Bernard STIEGLER, 1998.

${ }^{14}$ APPADURAI, 2001.

${ }^{15}$ APPADURAl, 2001, p. 46.

${ }^{16}$ APPADURAl, 2001, p. 49.

${ }^{17}$ Eduardo SUBIRATS, 2001, p. 2. guardias privados de seguridad. Por otro lado, es una ciudad afectada por la muerte de la imagen, la representación y la mediación, es decir, la urbe de la imagen sin referente, ni objeto. La ciudad "actuvirtual"13 de la in-mediación. La urbe plegada y desplegada en las pantallas de la publicidad trasnacional. Como señala Arjun Appadurai: "14 "ahora somos conscientes de que, con la llegada" de las redes de comunicación a distancia, "cada vez que nos sentimos tentados a hablar de la aldea global, debemos recordar" que se están produciendo "comunidades 'sin sentido de lugar'".

Appadurai trabaja estas dislocaciones desde los "paisajes" que las conforman y propone cinco dimensiones de flujos culturales globales: 1. Paisaje étnico, 2. Paisaje mediático, 3. Paisaje tecnológico, 4. Paisaje financiero y 5. Paisaje ideológico. "La palabra 'paisaje' hace alusión a la forma irregular y fluida (...) que caracterizan tanto al capital internacional como a los estilos internacionales de vestimenta". ${ }^{15}$ El paisaje mediático involucra tanto a la distribución de equipamiento electrónico necesario para la producción y diseminación de la información, como a las imágenes del mundo producidas y puestas en circulación por estos medios. Son las ciudades de la comunicación a distancia, de las audiencias desterritorializadas que se "imaginan" las urbes. "Dado que estas audiencias ven las líneas que separan los paisajes realistas de los ficticios de manera borrosa y poco clara, cuanto más lejos están situadas respecto de una experiencia directa de la vida metropolitana, mayor es la probabilidad de que construyan mundos imaginados, quiméricos, estetizados", producto de la fantasía, fundamentalmente "si se los mira con los criterios de alguna otra perspectiva y lugar del mundo, es decir, desde otros mundos imaginados". 16

Es, por ejemplo, el caso de Tijuana que frente a la ciudad habitada por masas empobrecidas de trabajadoras y trabajadores, están las imágenes de la vivida noche y la prostitución, famosas desde la edad dorada de Hollywood. En el paisaje mediático, los sitios web anuncian esos suburbios como "un paraíso exótico en cuyas salas de fiestas los turistas pueden perderse en fantásticas aventuras". Puerto franco de "prostitución multirracial barata". La sociología postmoderna de Estados Unidos "celebra sus paisajes híbridos: el mestizaje de los signos de la civilización posmoderna - las geometrías rutilantes de arquitecturas comerciales, los símbolos del consumo de masas, las highways y los mensajes" de la comunicación - con la riqueza "pluriétnica del México profundo, y los símbolos de su fragmentación, su destrucción cultural, y su empobrecimiento colonial y poscolonial". ${ }^{17}$

Hasta hace unas décadas, las imágenes emblemáticas de las principales capitales latinoamericanas eran 
las chimeneas y los barrios obreros. Actualmente, son los carteles de publicidad trasnacional que saturan hasta la contaminación visual todas las vías rápidas y los monumentos arquitectónicos postmodernos; los altos edificios corporativos, de vidrio reflejante (similares a grandes pantallas televisivas) que en Montevideo, Porto Alegre, Buenos Aires o Santiago de Chile cambiaron la mayor parte de los distritos, y ocuparon sectores enteros de la ciudad, sustituyendo a los tradicionales barrios y espacios de mediación por simulacros-virtuales donde el sujeto se fagocita en la pantalla. Múltiples ciudades en una ciudad, de países en un país...

\section{Sobre las ciudades invisibles}

En esa multiplicidad de urbes nos encontramos con las ciudades invisibles, "sueño que nace del corazón" de las propias ciudades invisibles. Las ciudades de Calvino se distribuyen en "memorias", "deseos", "signos", "trueques" (no sólo económicos sino también de palabras, de recuerdos). Son ciudades felices que cambian permanentemente de formas y se desvanecen y esconden en las ciudades infelices. Algunas tienen "ojos", nombres de mujeres y cielos. Y otras se encuentran "escondidas" y son "sutiles". Es así, que las ciudades son un conjunto mezclado y heterogéneo (heterotópico) que integra todas esas características. En el final del largo relato se puede leer:

Polo: - El infierno de los vivos no es algo por venir; hay uno, el que ya existe aquí, el infierno que habitamos todos los días, que formamos estando juntos. Hay dos maneras de no sufrirlo. La primera es fácil para muchos: aceptar el infierno y volverse parte de él hasta el punto de dejar de verlo. La segunda es riesgosa y exige atención y aprendizaje continuos: buscar y saber quién

${ }^{18}$ CALVINO, 1999, p. 117. y qué, en medio del infierno, no es infierno, y hacer que dure y dejarle espacio..$^{18}$

Un ejemplo de las ciudades nómadas y deseantes, es el caso de la fundación de Zobeida: "ciudad blanca, bien expuesta a la luna, con calles que giran sobre sí mismas como un ovillo". Se cuenta de su fundación que "hombres de naciones diversas tuvieron el mismo sueño, vieron una mujer que corría de noche por una ciudad desconocida, la vieron de espaldas, con el pelo largo, y estaba desnuda. Soñaron que la seguían". Después de muchas vueltas la perdieron. "Después del sueño buscaron aquella ciudad"; no la encontraron pero sí se encontraron entre ellos. Por tanto, "decidieron construir una ciudad como en el sueño". Las calles fueron diseñadas de acuerdo al recorrido que cada uno había realizado; "en el punto donde había perdido las huellas de la fugitiva, cada uno ordenó los espacios y los 
19 CALVINO, 1999, p. 88.

${ }^{20}$ Gilles DELEUZE y Félix GUATTARI, 2000 , p. 54.

${ }^{21}$ DELEUZE y GUATTARI, 2000, p. 54.

${ }^{22}$ CALVINO, 1999, p. 13-14. muros de manera distinta que en el sueño, de modo que no pudiera escapársele más". Ninguno de ellos, ni en el sueño ni en la vigilia, vio nunca más a la mujer. "Las calles de la ciudad eran las que recorrían todos los días para ir al trabajo, sin ninguna relación ya con la persecución soñada". Que, además, hacía tiempo que estaba olvidada. "De otros países llegaron nuevos hombres que habían tenido un sueño como el de ellos y en la ciudad de Zobeida reconocían algo de las calles del sueño, y cambiaban de lugar galerías y escaleras para que parecieran más al camino de la mujer seguida y para que en el punto donde había desaparecido no le quedara modo de escapar". Los que recién llegaban no entendían que era lo que atraía a tanta gente a Zobeida, a "esa ciudad fea, a esa trampa". ${ }^{19}$ En Zobeida se encuentra la ciudad cotidiana (del trabajo, el estudio, la recreación) con la ciudad invisible de los deseos. Sería tan tentador establecer un mapa de Zobeida, esa ciudad invisible, con los calcos de un rizoma: "A diferencia de los árboles o de sus raíces, el rizoma conecta cualquier punto con otro punto cualquiera, cada uno de sus rasgos no remite necesariamente a rasgos de la misma naturaleza; el rizoma pone en juego regímenes de signos muy distintos e incluso estados de nosignos". ${ }^{20}$ Zobeida, al igual que el rizoma, conforma: "un sistema acentrado, no jerárquico y no significante, sin General, sin memoria organizadora o autómata central" ${ }^{21}$ y se diseña únicamente a partir de los estados deseantes que circulan.

\section{Cludades invisibles y heterotópicas}

El texto de Calvino se presenta como una serie de relatos de viaje que Marco Polo hace al emperador de los Tártaros: Kublai Kan. Calvino aclara que "en la realidad histórica, Kublai", descendiente de Gengis Kan, "era emperador de los mongoles, pero en su libro Marco Polo" lo llama Gran Kan "de los Tártaros y así quedó en la tradición literaria". ${ }^{22}$ Marco Polo - el mercader veneciano que en el siglo XIII llega a la China como embajador del Gran Kan, después de recorrer buena parte del Lejano Oriente - se convierte, en el texto de Calvino, en el nómada postmoderno que relata la multiplicidad y las diferencias de las ciudades. Esa urbanidad femenina, que desde la denominación de mujeres, entrampa a los hombres. Éstos no tienen salida porque el laberinto femenino no les permite escapar. Es la ciudad otra que desarticula el espacio urbano postpatriarcal de identidades cerradas y trazadas por los hombres. El diseño masculino de poder uniforme, homogéneo, sin grandes novedades. Frente a él, el laberinto, el rizoma y las heterotopías de las ciudades invisibles, donde la representación se transforma en una trampa de si misma. Ya no más 
${ }^{23}$ FOUCAULT, 1984, p. 3.

${ }^{24}$ FOUCAULT, 1986.

${ }^{25}$ FOUCAULT, 1984, p. 6. espacio representativo sino la multiplicidad de las diferencias. Los heterotópicos son espacios heterogéneos, de encrucijadas y metamorfosis, por oposición a las utopías, son "reales", "efectivos", "están diseñados en la institución misma de la sociedad" y son "especies de contra emplazamientos". Son lugares que están fuera de todos los lugares, aunque sean sin embargo localizables. ${ }^{23}$

En esa destrucción del espacio de la representación se transita a/y/con el "afuera". Se le arranca al lenguaje la manera de ser del discurso y se descubre su propio ser como una claridad repentina que dilucida una distancia más que un doblez, "una dispersión más que un retorno de los signos sobre sí mismos". El afuera destrona el reino de la representación y, por tanto, de la mediación. En ésta "el espacio de encuentro" (symbolos) está en "ruinas", separado, desgarrado (diabolos), alejándose el lenguaje de las cosas.

La búsqueda de las similitudes - última rémora del pensamiento en estado salvaje bien estudiada por Michel Foucault ${ }^{24}$ en Las palabras y las cosas - aleja el espacio común donde se encontraban las hierbas y las estrellas. Pensamiento heterotópico que se enfrenta a la "monarquía" occidental de la representación, se caracteriza por el vacío y el silencio. Es un pensamiento caótico, dionisiaco, cambiante y mutante, un no-lugar donde la palabra se desarrolla a sí misma en un espacio neutro, sin límites y sin tiempo, que no es ya el espacio clásico y cerrado de la representación. Una de las características de las heterotopías es la yuxtaposición "en un sólo lugar real" de múltiples espacios, "múltiples emplazamientos que son en sí mismo incompatibles". ${ }^{25}$

\section{Ciudades sexuales}

En Diario del ladrón, Jean Genet llama a su espacio invisible: "España". Esa nominación es la de su momento de tránsito ${ }^{26}$ porque Genet cruza fronteras, deambula, desterritorializa el territorio. Frente al etnocéntrico y patriarcal cierre de las fronteras de España o Europa - que discursivamente utiliza términos como ilegalidad o irregularidad - para controlar sus límites y la inminente llegada de los otros. Contra este carácter, Genet salta las normas, no tiene papeles, cruza las fronteras y deambula por las ciudades:

Volví a Francia. Crucé la frontera sin inconvenientes, pero tras haber recorrido algunos kilómetros por la campiña francesa me pararon unos gendarmes. Mis harapos eran demasiado españoles.

- iDocumentación! 
27 GENET, 1994, p. 88.

${ }^{28}$ CLIFFORD, 1999.

29 Ulf HANNERZ, 1997.

30 CLIFFORD, 1999.

${ }^{31}$ HANNERZ, 1997.

32 DELEUZE y GUATTARI, 2000.

${ }^{33}$ DELEUZE, 1994, p. 14.

${ }^{34}$ En ningún caso se pretende confundir los estudios de género con el feminismo como tal. Este último término es uno de los objetos de estudio del primero.
- Enseñé unos trozos de papel sucio y hechos trizas a fuerza de doblarlos y desdoblarlos.

- ¿Y el carné?

- ¿Qué carné?,

Acababa de enterarme de la existencia del humillante carné antropométrico. Se les da a todos los vagabundos. Hay que visarlo en cada gendarmería. Me metieron en la cárcel. ${ }^{27}$

\section{Ciudades nómadas}

Finalmente, ayudados por Genet, nos encontramos con las ciudades nómadas. Mientras el mundo tiende a encogerse, a homogeneizarse, a acercarse producto del incremento de los viajes transoceánicos, se tiende a pensar que aumenta el nomadismo por los incesantes traslados de personas. Sin embargo, es preciso considerar que no todo movimiento implica nomadismo. Es así que hay autores que antes de nomadismo prefieren utilizar otras nociones para referirse a la actualidad. James Clifford considera al nomadismo como un primitivismo postmoderno y, por tanto, concibe más adecuadas las nociones de culturas peregrinas de viaje ${ }^{28}$ y se refiere, además, al resurgimiento, debido a las conexiones trasnacionales, ${ }^{29}$ de las comunidades diaspóricas. ${ }^{30}$ Por su parte, Ulf Hannerz retoma la noción de ecúmene. ${ }^{31}$ No obstante, son Gilles Deleuze y Félix Guattari32 quienes les dan un estatuto liberador a la idea de nomadismo y consideran, al respecto, que el migrante y el nómada no son las mismas figuras aunque se puedan confundir en algunos momentos. El nómada desterritorializa el territorio, abandona el sedentarismo y desafía los cierres de las fronteras. No vuelve al origen (llámese patria, ciudad o país) sino que siempre traza nuevos recorridos. El migrante recorre un espacio mientras que el nómada se mueve. Por tanto la diferencia está en que el "espacio recorrido es pasado" mientras que el "movimiento es presente, es el acto" de recorrer. "El espacio recorrido es divisible, mientras que el movimiento es indivisible, o bien no se divide sin cambiar, con cada división, de naturaleza". ${ }^{33}$

En este contexto, es importante considerar, por su poder liberador, el término nomadismo, vinculándolo, además, a los estudios de género y a la característica versátil y excéntrica del feminismo. ${ }^{34}$ Las nómadas se ubican en los espacios de tipo rizoma que se caracterizan por la multiplicidad de entradas, rompen con la idea esencialista de la identidad y diseminan los territorios imposibilitando cualquier vuelta al origen. Volvemos a Calvino: La ciudad del nómada "existe y tiene un simple secreto: sólo conoce 
${ }^{35}$ BRAIDOTTI, 2004, p. 216.

${ }^{36}$ ZIZEK, 1999.

${ }^{37}$ BRAIDOTTI, 2004, p. 216.

${ }^{38}$ Emmanuel LÉVINAS, 2002.

${ }^{39}$ Pierre BOURDIEU, 2000. partidas y no retornos". La nómada es contracultural y su conciencia "es una forma de resistencia políica a toda visión hegemónica y excluyente de la subjetividad (...) representan la rebelión de los saberes sojuzgados". ${ }^{35}$ Como señala Slavoj Zizek: 36 "Hay que reconocer el impacto tremendamente liberador de la politización postmoderna de terrenos hasta entonces considerados apolíticos (feminismo, políticas gay y lesbiana, ecología, problemas de minorías étnicas y otras)". El hecho de que esos problemas "no sólo hayan sido percibidos como intrínsecamente políiticos sino que hayan dado a luz a nuevas formas de subjetivación política rediseñó todo nuestro paisaje político y cultural".

Como las ciudades sexuales de Genet, rechazan las fronteras y los servicios de seguridad que se encuentran protegiéndolas. "El estilo nómada alude a las transiciones y a los pasos sin destinos predeterminados ni patrias perdidas". La relación del nómada con la tierra es ecológicamente sustentable, hecha de "apegos transitorios y de frecuentaciones cíclicas"; como "antítesis del granjero, el nómade recolecta, cosecha e intercambia pero no explota la tierra". ${ }^{37}$ Por ello, la acción del nómada no transcurre en el centro de la ciudad sino en sus puertas y en sus afueras, donde las tribus nómadas de políglotas trotamundos se detienen para tomar un breve descanso y luego proseguir. Es así que el nomadismo tiene ritmo: es festivo, riesgoso y carnavalizante.

\section{Conclusiones}

El análisis de las transformaciones urbanas, motivadas por el crecimiento exponencial de las ciudades y sus proyecciones simbólicas, requiere, en muchas oportunidades, de un estudio de las diversas formas de imaginarse las ciudades que se encuentran en la literatura, la música, el cine, como mecanismos simbólicos que permiten evadirse ${ }^{38}$ de las ciudades homogéneas, frías, habitadas en grandes bloques de cemento del capitalismo postindustrial. Paralelamente, los énfasis de los análisis no siempre incluyen la vinculación entre esa ciudad del capitalismo postindustrial con el postpatriarcado que ha buscado diferentes formas de continuar sometiendo a las sexualidades otras al poder masculinizante que concibe una representación moldeada de las ciudades desde los cristales metafísicos de la "dominación masculina". ${ }^{39}$ Es por ello que, frente a esos análisis, este ensayo presenta la opción de evadirse de las ciudades postpatriarcales, multiplicando las imaginaciones, los relatos que sobre las urbes circulan, asumiendo el laberíntico espacio antirrepresentativo de las ciudades rizomáticas, nómadas y heterotópicos de esos otros no lugares en los que habita la carnavalizante presencia de las otredades sexuales. 


\section{Referencias bibliográficas}

APPADURAI, Arjun. La modernidad desbordada. Montevideo: Trilce, 2001.

BOURDIEU, Pierre. La dominación masculina. Barcelona: Anagrama, 2000.

BRAIDOTTI, Rosi. Feminismo, diferencia sexual y subjetividad nómade. Barcelona: Gedisa, 2004.

CALVINO, Italo. Las ciudades invisibles. Madrid: El Mundo, 1999.

CLIFFORD, James. Itinerarios transculturales. Barcelona: Gedisa, 1999.

DELEUZE, Pilles. La imagen-movimiento. Estudios sobre cine. Barcelona: Paidós, 1994.

DELEUZE, Pilles; GUATTARI, Félix. Mil mesetas. Capitalismo y esquizofrenia. Valencia: Pre-Textos, 2000.

DERRIDA Jacques; STIEGLER Bernard. Ecografías de la televisión. Buenos Aires: EUDEBA, 1998.

FOUCAULT, Michel. "De los espacios otros". Conferencia dictada en Cercie des Études Architecturais, publicada en Architecture, Mouvement, Continuité, n. 5, octubre 1984.

Las palabras y las cosas. México: Siglo XXI, 1986.

GARCÍA CANCLINI, Néstor. La globalización imaginada. Buenos Aires: Paidós, 1999.

GENET, Jean. Diario del ladrón. Barcelona: Seix Barral, 1994.

JAMESON, Fredric. Teoría de la postmodernidad. Madrid: Trotta, 1996.

HANNERZ, Ulf. Conexiones transnacionales. Cultura, gente, Iugares. Valencia: Cátedra y Universitat de València, 1997.

LÉVINAS, Emmanuel. De la evasión. Madrid: Arena, 2002.

RODRÍGUEZ MONEGAL, Emir. "Onetti o el descubrimiento de la ciudad”. Capítulo Oriental, Montevideo, n. 28, 1968.

SILVA ECHETO, Víctor; BROWNE, Rodrigo. Escrituras híbridas y rizomáticas. Pasajes intersticiales, pensamiento del entre, cultura y comunicación. Sevilla: Arcibel, 2003.

. Antropofagias. Las indisciplinas de la comunicación. Madrid: Biblioteca Nueva, 2007.

SUBIRATS, Eduardo. "Encontré una diosa verdadera en Tijuana". Revista Brecha, Montevideo, 16 febrero 2001.

VATIIMO, Gianni. "El estructuralismo y el destino de la crítica". En: Henciclopedia. Consultado en la web: http:// www.henciclopedia.org.uy. 1998.

ZIZEK, Slavoj. "Dije economía política, estúpido". En: Antroposmoderno. Consultado en la web: http:// www.antroposmoderno.com. 1999.

[Recebido em janeiro de 2008 e aceito para publicação em setembro de 2008] 


\section{The Invisible Clties: Nomadic Heterotoples and Post Patriarchy}

Abstract: Many cities may be found in one city: some of them are visible and some others are invisible, but all of them are produced in the heterotopic space of the (heterogenic and nomadic) other. The diverse ways of imagining the cities (from literature, cinema, music) allow to transgress the postpatriarchal cities, from a nomadic rhizomatic and transversal conception of feminism, and answer creatively and aesthetically to the cities which have been designed under the auspices of late capitalism: homogeneous, (in)different, non localized, male chauvinist (without identity, neither relationships, nor histories) places. When facing them, the figure of the other cities, of the multiplicity of the differences and singularities, of what has been cast aside, certainly sprouts: gender studies and their demands (sexual and nomadic cities), different, ambiguous, ambivalent, eccentric, wanting and heterotopic cities (with heterogeneous, changing and fractured spaces). Key Words: Invisible Cities; Nomadism; Heterotopia; Patriarchy; Postpatriarchy. 